\title{
Degradation of 2, 4, 6-trinitotoluene in aqueous solution by ozonation and multi-stage ozonation biological treatment
}

\author{
G. El Diwani; *S. El Rafie; S. Hawash \\ National Research Center, Department of Chemical Engineering and Pilot Plant, National Research Center, \\ Cairo, Egypt \\ Received 20 November 2008; $\quad$ revised 8 July 2009; accepted 22 August 2009; $\quad$ available online 1 September 2009
}

\begin{abstract}
The objective of this study was to explore the extent of 2,4,6-trinitrotoluene synthetic solution and red water mineralization by comparing conventional direct ozonation and multi-stage ozonation-biological treatment process. The alkaline hydrolysis was used for remediation 2, 4, 6-trinitrotoluene and red water at $\mathrm{pH}=10.9$. Nevertheless, the hydroxyl radicals would be generated by ozone decomposition with ozone dose of $0.177 \mathrm{~g} / \mathrm{L}$. The samples were subjected to chemical oxygen demand and total organic carbon analysis to monitor pollutants removal. The rate of 2, 4, 6-trinitrotoluene and red water pollutants degradation were quantified using high performance liquid chromatography. 2, 4, 6-trinitrotoluene synthetic solution resulted $55.5 \%$ chemical oxygen demand removal by $3 \mathrm{~h}$ direct ozonation. Following direct ozonation the biological treatment twenty four hours chemical oxygen demand reached $98.9 \%$ and $98.7 \%$ removal using humic acid and river water $1 \%(\mathrm{v} / \mathrm{v})$ inoculation singly and respectively. Conventional direct ozonation showed non significant change in total organic carbon degradation. While on using multi-stage ozone-biological treatment process where humic acid and/or river water were used as inoculums singly and respectively, total organic carbon fulfilled $73 \%$ and $98.3 \%$ removal. The process was one hour direct ozonation and followed by three days multistage ozone-biological treatment. In multi-stage ozone-biological treatment process, ozonation was effective to decompose total organic carbon and to produce biodegradable dissolved organic carbon easily removed by ozone oxidation up to $98.3 \%$ in 2,4,6-trinitrotoluene synthetic solution. Pollutants removal achieved $99 \%$ in authentic red water effluent using river inoculation $1 \%(\mathrm{v} / \mathrm{v})$ in 5 days. Nuclear Magnetic Resonance and Fourier Transformation Infra Red methods were performed to confirm types of pollutants content in red water.
\end{abstract}

Keywords: Chemical oxidation; Pollutants mineralization; Red water; Removal, Total organic carbon

\section{INTRODUCTION}

Nitro aromatic compounds are used in many industrial processes, including the preparation of pesticides, explosives, textile and paper. Therefore, these compounds are often detected as water pollutants as a result of their release in industrial effluents (Song et al., 2007). 2, 4, 6-trinitrotoluene(TNT) is a common pollutant which has been the most widly used nitroaromatic explosive and is known to be mutagentic, carcinogenic and toxic to aquatic and terrestrial organisms (Won and Disalvo, 1976). Therefore, the United States Environmental Protection Agency has classified TNT as a possible human carcinogenic (class $\mathrm{C}$ ) and has issued the health advisories for TNT to less than 0.002 $\mathrm{mg} / \mathrm{L}(\mathrm{USEPA}, 2002)$. Soil and ground water contaminated by TNT and its derivatives is a worldwide environmental problem related to production sites, ammunition plants and demilitarization activities. Alkaline hydrolysis \*Corresponding Author Email: shelrafie0000@yahoo.com Tel.: +2 333 71433; Fax: +2 35570931
(Bandstra et al., 2005) and zero valent iron (Thorn et al., 2004) treatments have been successfully applied for TNT degradation in the water and soil treatments. However, these two technologies proceed through reductive pathways leading to the formation of an uncharacterized polymeric material of unknown toxicity, mainly in soil, upon prolonged TNT treatment (Thorn et al., 2004). Incineration is the most effective remediation method but is expensive and generates concern about air emissions. Supercritical water oxidation (SCWO) is a high temperature and pressure technology that utilizes the properties of supercritical water to destroy organic compounds and toxic wastes. The (SCWO) has been used to treat streams, sludgs and contaminated soils (Svanstrom et al., 2004; Chang and Liu, 2007). Bioremediation is often effective, but cannot be applied in highly contaminated sites, requires long treatment times and often produces toxic and/or mutagenic byproducts (Jarvis et al., 1998; Adams and Guzmán- 
Osorio, 2008). Conventional biological wastewater treatment processes (eg. activated sludge) are not effective in treating the residues because the electron - withdrawing nitro constituents in these explosives inhibit the electrophilic attack through enzymes (Behera et al., 2007; Chen et al., 2007). Advanced oxidation processes (AOPs) have been shown great potentials for the treatment of a large range of refractory organic pollutants in waters and soils. AOPs rely on the generation of strong oxidants, such as hydroxyl radicals. This type of radicals can be easily generated using hydrogen peroxide and dissolved iron (Fenton chemistry), but low $\mathrm{pH}$ conditions $(\mathrm{pH}=3)$ are required to prevent the precipitation of iron. Fenton's reaction has also been used to treat TNT contaminated aqueous solution often resulting incomplete degradation and partial mineralization with accumulation of short chain carboxylic acid at the end of the reaction time (Chen et al., 2005; Yardin and Chiron, 2006). Unlike the Fenton's reagent, the reaction of iron minerals with hydrogen peroxide can effectively catalyze. When TNT undergoes chemical reduction under anaerobic conditions, the nitro groups is the original structure can be transformed sequentially to amino groups (Barrows et al., 1996), ultimately yielding 2,4,6-trinitrotoluene (Hofstetter et al., 1999). Because intermediates are of environmental concern, field applications relying on the reduction of TNT using iron species must also consider subsequent reactions such as biodegradation or covalent binding of the intermediate products to natural organic matter, which can effectively irreversible (Agrawal and Tratnyek, 1996). Vohara and Tanka (2002) studied photo-catalytic degradation of TNT while (Li et al., 1998) studied UV-catalytic Fenton oxidation for complete mineralization. The main problem of (AOPs) lies in the high cost of reagents such as ozone, hydrogen peroxide or energy source such as ultra violet light. For the photocatalytic ozonation methods the energy demand of the $\mathrm{O}_{3} / \mathrm{TiO}_{2} / \mathrm{UV}$ could be considerably decreased by the use of solar irradiation and in situ electrochemical $\mathrm{O}_{3}$ generation (Agustina et al., 2005). The organic compounds (e.g. DNT isomers and TNT were gradually mineralized by ozonation of which oxidation efficiency was about $78.0 \%$ after $7 \mathrm{~h}$ treatment (Sotelo and Beltrain, 1989). Lin and Kiang (2003) studied mineralization of dinitrotoluene (DNT) and TNT in spent acid toluene nitration process by ozone and $\mathrm{UV} / \mathrm{O}_{3}$. Peyton and Glaze (1988) studied the generation of hydroxyl radicals by photo-ozonation and stated that it should result in higher oxidation efficiency of organic compounds in comparison with that of ozone. Chemical oxidation methods (eg. AOPs) are also not considered effective because the nitrofunctional groups inhibit oxidation (Barreto-Rodrigues et al., 2008). Lin and Kiang (2003) combined physical and biological treatments consisted of air stripping, modified Fenton oxidation and sequencing batch reactor method. They achived lowering of the wastewater COD concentration from as high as $80,000 \mathrm{mg} / \mathrm{L}$ to below $100 \mathrm{mg} / \mathrm{L}$ and the effluent was reused. Esplugas et al. (2002) added that although low costs were obtained with ozonation for phenol as TNT by-products during remediation in aqueous solution, but in the ozone combinations, the best results were achieved as $\mathrm{UV} / \mathrm{H}_{2} \mathrm{O}_{2}$ showed the highest degradation rate. Ozone followed by biological treatment is one of the promising processes to mineralize nitro aromatic compounds and to remove TOC completely from raw water (Fahmi et al., 2003). Ozone transforms refractory natural organic matter (NOM) to biodegradable form. i.e.; biodegradable dissolved organic carbon (BDOC). BDOC produced by ozonation is removed by biodegradation in the subsequent biological treatment. Therefore, dissolved organic carbon (DOC) removal in this process is dependent on the production of BDOC in the ozonation. The transformation of refractory DOC to BDOC by ozonation may be inhibited by BDOC) itself produced by ozonation, because BDOC may also consume ozone. Yasui et al. (1992) reported that reozonation of organic matter after biological treatment produced new assimilable organic matters (Yasiu and Miyaji, 1992; Imo et al., 2007). They added that ten times of $1 \mathrm{~min}$ ozonation and subsequent biodegradation removed $95 \%$ of DOC, where as continuous ozonation for 64 min followed by biological treatment removed only $70 \%$. Besides, TNT is resistant to reaction with acids, but like all nitro compounds, it reacts easily with bases. The reactions of TNT with basis are often accompanied by intense color (violet, red or brown colors depending on the alkali system). Due to low solubility of TNT in water $\left(6 \times 10^{-4} \mathrm{M}\right)$ at $25^{\circ} \mathrm{C}$, hydrolysis of TNT has often been performed in an alcohol as co-solvent system. The use of excess strong base is probably the most efficient means of ensuring that hydrolysis is driven to completion. However elevated temperature $\left(60^{\circ} \mathrm{C}-155\right.$ ${ }^{\circ} \mathrm{C}$ ) and often elevated pressure (up to $14 \mathrm{Atm}$ ) may be needed in a strong base solution $(\mathrm{pH}>12)$ representing vigorous process. These reaction conditions must be carefully monitored to prevent spontaneous and violent exothermic reaction where $\mathrm{NaOH}, \mathrm{KOH}, \mathrm{NH}_{4}(\mathrm{OH})$ and $\mathrm{Na}_{2} \mathrm{CO}_{3}$ have been used. Hydrolysis rate of TNT 
increase from $5.3 \mathrm{~g} / \mathrm{h}$ to $40 \mathrm{~b} / \mathrm{L}$ at the same $\mathrm{NaOH}$ concentration (3.4 $\mathrm{M}$ or $12 \%$ by wt) and same temperature $\left(95^{\circ} \mathrm{C}\right)$, but changing stirring from gentle to vigorous agitation (Proposal submitted in response to U.S. Army Solicatation, 1997).

In this study, different experiments were carried out in which conditions, including $\mathrm{O}_{3}$ dose, ozonation time, $\mathrm{pH}$ and initial TNT concentration were varied to examine the influence of these factors on the extent of TNT degradation. Pollutants mineralization was detected by measuring COD and TOC values in tested samples before and after treatment. After applying the optimum conditions, multi-stage ozone-biological treatment process was performed using prepared (humic acid and river surface water) with varying contact time to achieve complete mineralization of TNT and red-water tested sample. HPLC (high performance liquid chromatography) analysis was used for determination of pollutants complete removal in tested samples. This work has been performed in the National Research Center, Chemical Engineering and Pilot Plant Department, Cairo, Egypt, November 2007.

\section{MATERIALS AND METHODS}

TNT crystalline form of $>95 \%$ purity obtained from local industry producing explosive materials and was used without further purification.

Red water was obtained from the effluent produced by the second washing designed to extract the organic impurities and stored under refrigeration for later use.

Humic acid was prepared by evaporating $1 \mathrm{~L}$ of supernatant of sewage wastewater on water bath at $40^{\circ} \mathrm{C}$. The solution was stirred $80 \mathrm{~min}$ and then filtered to remove insoluble residues before evaporation. The solution was evaporated till 1/5 of its original volume and stored in refrigerator for later use. River water (surface water) was collected and filtered to be used for inoculation and stored under refrigeration for later use.

Phosphate buffer was prepared in distilled water by reaction of calculated amounts of sodium hydroxide solution and phosphoric acid solution. A $1000 \mathrm{~mL} \mathrm{TNT}$ aqueous stock solution was prepared by dissolving $1 \mathrm{~g}$ of TNT in $1 \mathrm{~L}$ buffer solution (after dissolving TNT in 3 $-5 \mathrm{~mL}$ of acitonitrilel) and stored at $4{ }^{\circ} \mathrm{C}$ (Song et al., 2007). Various strengths were made from the stock by the appropriate dilution with buffer.

Ozone is produced by Fisher ozonator by passing 20 L/h of oxygen at 5 Atm., through the generator Fig. 1. Oxygen is supplied by compressed bottled gas. Electrical input is changed from $120-240$ MA in order to vary ozone concentration output. Leakage of ozone from reactor is detected by potassium iodide trap (1). Ozone concentration in the gas stream is measured by iodine / thiosulphate, using standard iodometric method. Chemical oxygen demand and total organic carbon were performed and measured according to APHA (1999) and were completed using HACH- DR 2000 spectrophotometer. MSDS MO 174 vials were incubated during $120 \mathrm{~min}$ at $150^{\circ} \mathrm{C}$ and at $100^{\circ} \mathrm{C}$, respectively. Air compressor (air flow rate $680 \mathrm{~mL} / \mathrm{min}$ and 220 Volt) for aerating the samples during inoculation. Fourier transform infra red (FTIR) spectrum of the red-water sample was recorded using Jasco 460 FTIR spectrometer from 600 to $4000 / \mathrm{cm}$. Nuclear Magnetic Resonance (NMR) was recorded on Varian 200 M Hz, Gemini, 200 instruments. HPLC was performed with HPLC system (Waters) equipped with model 600 delivery system, model (Waters 486). UV detector set at $254 \mathrm{~nm}$ and the data recorded by millennium chromatography. Manager software 2010 (Waters, Milford MA 01757).

Reverse phase $\mathrm{C}_{18}$ Nucleosil column 250 XY mm, 10 $\mu \mathrm{m}$ (Macherey- Nagyel. CO, Germany was used. Mobile

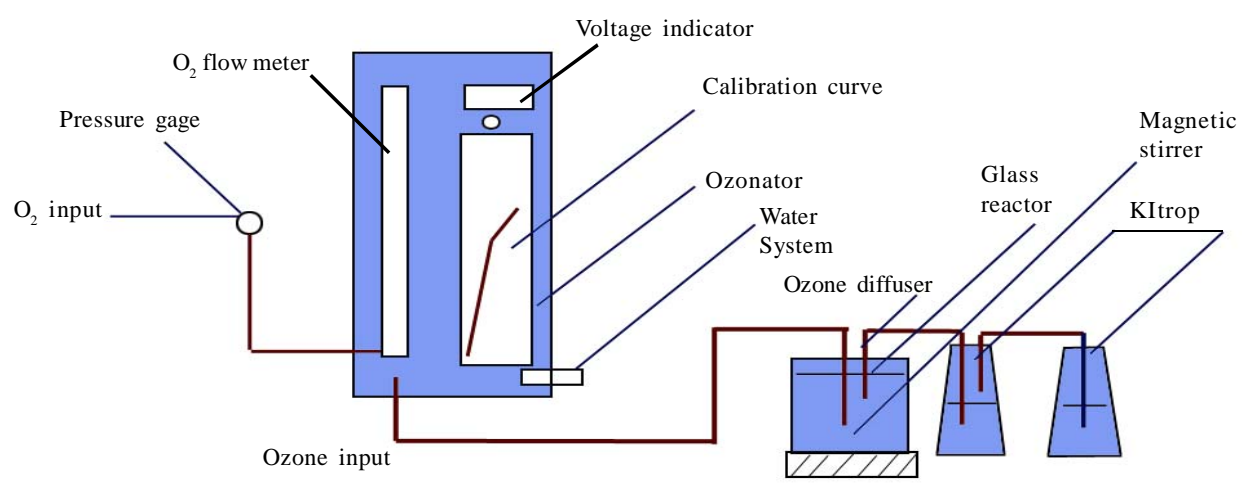

Fig. 1: Experimental set-up of the ozonation system 
phase methanol : water $(1: 1)$ isocratic program, flow rate $1 \mathrm{~mL} / \mathrm{min}$.

The ozone is dispersed directly into the prepared synthetic-TNT samples or authentic red-water samples and mixed perfectly with magnetic stirrer. Residual ozone contaminated in the exit gas is absorbed by potassium iodide solution and determined by titrimetric technique. The $200 \mathrm{~mL}$ of the TNT-synthetic solution (of $20 \mathrm{mg} / \mathrm{L}$ prepared from $100 \mathrm{~mL}$ TNT stock solution by appropriate dilution with buffer) or ( $200 \mathrm{~mL}$ authentic red-water with appropriate dilution with buffer) are agitated by a magnetic Teflon bar at room temperature $\left(20^{\circ} \mathrm{C}\right)$. Gas of different ozone concentrations is dispersed into the solution through the orifice glass tube for $(1,1.5,2$ and 3 h) to give the predetermined ozone application rates. Ozone flow is stopped, stirring is continued in the closed batch system for both TNT degradation in synthetic solution and/or nitro-amines degradation in red water. Ozone concentrations are determined at time intervals, for reaction time 15, 20, 30 and $60 \mathrm{~min}$. The $1 \mathrm{~h}$ and $3 \mathrm{~h}$ ozone reaction time were selected as effective time for pollutants degradation. The extent of degradation was evaluated by COD and TOC spectrophotometer mesurements.

A well - mixed red - water sample was evaporated in evaporating dish and dried to constant weight in an oven set at $70-80^{\circ} \mathrm{C}$. The sample was grounded dryby a mortar and pestle to fine powder. The powder was packed into a black-filled mount with a circular cavity that was $15 \mathrm{~mm}$ in diameter. The samples were scanned using FTIR spectrum of the red-water samples after evaporation and drying. Pollutants present in red - water recorded using FTIR spectrum from $600-4000 \mathrm{~cm}^{-1}$, Material Data (2003).

Nuclear Magnetic Resonance spectrum was measured at ambient temperature, 107 scans, using minimum mg of sample dissolved with internal standard. Spectrometer operating in the FT model at $199.9752 \mathrm{MHz}$ under total proton decoupled conditions. The red-water sample was dissolved in 1mL DMSO. A 39.4 degree pulse flipping angle, a $5000 \mathrm{~ms}$ pulse width and a $1.994 \mathrm{sec}$ acquisition time was used.

EPA standard method 8330 for trace analysis of explosive residues by HPLC using UV detector was monitored at $254 \mathrm{~nm}$. Reverse phase $\mathrm{C}_{18}$ nucleosil column 250 XY mm, $10 \mu \mathrm{m}$ (Macherey- Nagyel. CO, Germany) was used. Mobile phase methanol water (1:1) isocratic program, flow rate $1 \mathrm{~mL} / \mathrm{min}$. Calibration of the HPLC was performed using external standards with concentrations ranging from $0-10,000 \mu \mathrm{g} / \mathrm{L}$. Calibration of the standard solutions was prepared in both acitonitrial and deionized water $(1: 1)$ using serial dilutions of the stock solution. Five standard concentrations were prepared in all cases for HPLC calibration. All samples were prepared as standard and placed in ultrasonic bath more than $2 \mathrm{~h}$. After sonication, the samples were allowed to settle for $30 \mathrm{~min} .5 \mathrm{~mL}$ of supernatant was removed and combined with $5 \mathrm{~mL}$ of calcium chloride solution ( $5 \mathrm{~g} / \mathrm{L})$. The mixture was shaken and then left to stand for $15 \mathrm{~min}$. The supernatant was introduced into HPLC using automatic injector. Transformation products were identified by retention time in the system. Sorbed concentrations were estimated as the difference between the original concentration and final aqueous concentration.

\section{RESULTS AND DISCUSSION}

Table 1 represents the characteristics of authentic red water. Fig. 2 shows the pollutants contents in red water which corresponds to dissolved by-products obtained in wastewater effluent from explosives production plant. The solid part from the effluent wastewater represents the TNT from the production plant. The solid part was studied as synthetic solution treatment, which is prepared through the study by hydrolysis in buffer solution. The following parameters affecting pollutants degradation were studied. Changing ozone doses $(0.015,0.070,0.112,0.177 \mathrm{~g} / \mathrm{L})$ each at contact time $5,15,30$ and $60 \mathrm{~min}$, respectively were applied to samples at $\mathrm{pH} 10.9$, showed optimum ozone dose $0.177 \mathrm{~g} / \mathrm{L}$ at $300 \mathrm{~mA}$. The results indicated that ozone dose had a positive effect on TNT degradation. All ozone doses tested less than 0.177 $\mathrm{g} / \mathrm{L}$ indicated negative effect on TNT degradation determined by no remarked COD or TOC reduction.

This was attributed to increasing ozone dose, increases the area of the gas - liquid interface, which resulted in an increase of ozone concentration in the solution and an increase of the formation of the free radicals with a consequent increase in the rate of TNT degradation. This COD removal up to $55.5 \%$ was achieved at ozone dose $0.177 \mathrm{~g} / \mathrm{L}$ indicated by COD measurements. The actual optimum dose of ozone can be determined by the ozone / TNT ratio required for complete degradation (Vohara and Tanaka, 2002). Therefore, optimization of ozone dose is necessary to minimize energy consumption and amount of exhaust ozone gas. The effect of $\mathrm{pH}$ on pollutants degradation experiment was repeated over the range of $5-10$. Only $\mathrm{pH}$ value 10.9 , the TNT degradation rate increased. While at $\mathrm{pH}$ (5, 8 and 9) no significant degradation in 
TNT was indicated by measurements of COD and TOC values for tested samples. These results were attributed to the decomposition of ozone, as the solution became more basic. While to secondary oxidants such as hydroxyl radicals, results are more agreed with (Sivakumar et al., 2002). Hwang et al. (2005) achieved the highest $74 \%$ TNT reduction at $\mathrm{pH}$ of 11.9 and 2 days hydraulic retention time under steady-state conditions.

The effect of different initial TNT concentrations (4, $10,20 \mathrm{mg} / \mathrm{L}$ ) on degradation extents with ozone dose $0.177 \mathrm{~g} / \mathrm{L}$ was studied. The results showed that higher initial concentration led to a slower TNT degradation rate as indicated by COD values of (30, 150 and 430 $\mathrm{mg} / \mathrm{L}$ ) at optimum $\mathrm{pH}=10.9$ and ozonation time $3 \mathrm{~h}$. The overall degradation rate of TNT dependeds on number of hydroxyl radicals generated and the rate of release of hydroxyl radicals into the surrounding medium (Rauch and Drewes, 2005). FTIR spectroscopy was performed to red water dried sample to identify types of pollutants present. Various bands (1-12) (Fig. 2) in the spectrum were identified from which corresponding to alkenesstretching bands of $\mathrm{CH}$ and $\mathrm{C}=\mathrm{C}$ at wave number (3040 $-3010) / \mathrm{cm}$ and $(1680-1620) / \mathrm{cm}$. The wave number at (3040 -3010) and (1623 - 1622)/cm for Ph-CH=CH-R identified alkenes stretching bands and aromatic C-H and $\mathrm{C}=\mathrm{C}$. The bands at wave number $(1650-1340) / \mathrm{cm}$ could be due to ph- $\mathrm{NH}_{2}$ and bands at wave number (1350-1260)/cm represent the C-N group. The amides groups also represented at wave number (3375 - 3325)/ $\mathrm{cm}$ indicating primary amides. The carbonyl group $\mathrm{C}-\mathrm{O}$ stretch and the amide group $\mathrm{NH}_{2}$ represented a band at wave number $(1638-1618) / \mathrm{cm}$ identified group. The $\mathrm{C}=\mathrm{O}$ stretching bands at wave number $(1640-1540) / \mathrm{cm}$ identifies presence of ketones.

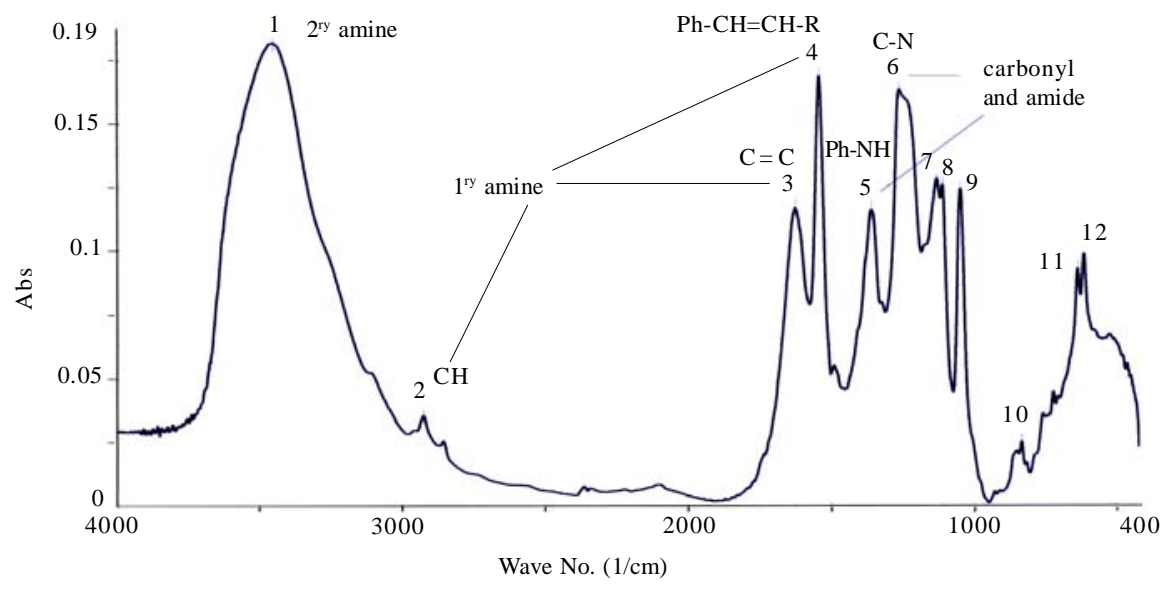

Fig. 2: FTIR- Chromatogram main pollutant present in red wastewater

Table 1: Characteristic of red-water, wastewater

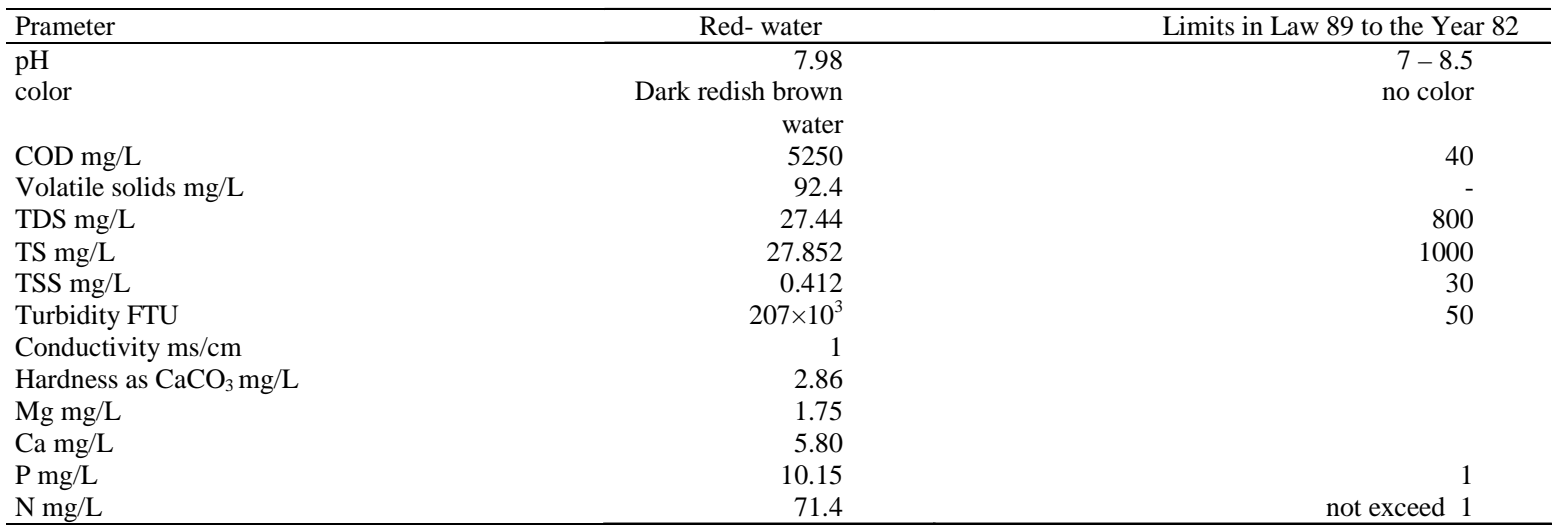


The broad band at wave number $(850-750) / \mathrm{cm}$ representing $\mathrm{N}-\mathrm{H}$ group and bands at wave number $(638$ -1022)/cm representing C-N group. The bands at wave number $\left(3500\right.$ - 3300) $\mathrm{cm}^{-1}$ stretching represented secondary amine.

NMR -Spectra for the dried red-water tested sample showed the $\mathrm{H}^{\star} \mathrm{NMR}$ chart in Fig (3) and Table (2) the signal at (2.5-2.2 ppm) (P-2h, $\left.\mathrm{CH}_{2}\right),(4.336 \mathrm{ppm})$ (Gamma protons) and (alpha protons). The broad band at (3.457ppm) indicated the DMSO while (7.738 ppm) indicated ethylenic and aromatic protons.

The biological treatment was performed by supplying appropriate amount of ozone dose 0.177 $\mathrm{mg} / \mathrm{L}$ to TNT synthetic solution of $20 \mathrm{mg} / \mathrm{L}$ concentration for each tested sample. Time of continuous ozonation was studied at (1, 2, 2.5 and $3 \mathrm{~h}$ ). COD and TOC analysis were subjected to evaluate the residual organic compounds contents (Fig. 4). The direct ozonated samples $1 \mathrm{~h}$ were then aerated for $10 \mathrm{~min}$ to remove residual ozone and were incubated with $1 \%(\mathrm{v} / \mathrm{v})$ of humic acid or $1 \%(\mathrm{v} / \mathrm{v})$ of river water as an inoculum, each singly and at ambient temperature for $24 \mathrm{~h}$. $20 \mathrm{~min}$ ozonation were followed to each inoculated sample to remove biodegradable dissolved organic carbon (BDOC) (Guest and Smith, 2002; Rauch and Drewes, 2005). COD achieved $72.5 \%$ and $94.6 \%$ removal when using one hour direct ozonation followed by one day humic acid or river water inoculation respectively. To perform multistage ozone-biological treatment, TNT and red-water tested samples were subjected to $3 \mathrm{~h}$ direct ozonation and followed by $72 \mathrm{~h}$ river water biological inoculation. Samples were subjected to 20 min ozonation after each $24 \mathrm{~h}$, to mineralize the BDOC produced through treatment performed.

After the ozonation, the samples were subjected to COD and TOC measurements to evaluate the effect of multi-stage ozonation biological treatment (MSOB). The treatment achieved $98.49 \%$ and $97.56 \%$ TOC removal for TNT and red-water samples, respectively (Fig. 5).

The optimum ozone dose and subsequent biodegradation was performed using samples of the authentic red water containing nitro-compounds was diluted and subjected to ozone treatment. The treatment followed the ( $1 \mathrm{~h}$ and $3 \mathrm{~h}$ ) ozonation singly with ozone dose $0.177 \mathrm{~g} / \mathrm{L}$, at $\mathrm{pH}=10.9$. The treated wastewater samples were then subjected to $10 \mathrm{~min}$ flashing with air to get rid of residual ozone before adding $1 \%(\mathrm{~V} / \mathrm{V})$ of river water as an inoculums at ambient temperature for $24 \mathrm{~h}$. After which, ozonation for 20 min was undertaken at same privous ozone dose. The tested samples were undertaken to COD and TOC measurements. These pervious treatment steps MSOB were repeated up to five days for $3 \mathrm{~h}$ direct ozonation process ( Fig. 5) and repeated up to eight days for $1 \mathrm{~h}$ direct ozonation treament process (Fig. 6). HPLC analysis was performed to detect extent of remediation as shown in Figs. 7-10a and $b$. High performance liquid chromatography (HPLC) analysis was subjected to evaluate the destructive effect of direct ozonation for $3 \mathrm{~h}$ and direct ozonation for $1 \mathrm{~h}$ both followed by multistage ozonation-biological treatment for complete mineralization of nitrogenous species have been studied. The HPLC chromatogram illustrates extent of pollutants removal from red water contaminated by nitro-amines till complete mineralization. The HPLC chromatogram of the original red water in Fig. 7 illustrates main peaks at retention time 1.044 and 1.141 besides trace of uracil at retention time 1.47 and phenols at 1.670 .

Fig. 8 shows the effect of direct ozonation on degradation of wastewater, including disappearance of main peaks and leaving uracil and phenols. Pollutants such as nitrobenzene was detected too. The $1 \mathrm{~h}$ direct ozonation increased the decomposition rate of the major pollutants at retention time 1.044 and 1.191 up to $93 \%$ and $89.75 \%$, respectively. The transformation products increased the content of uracil and phenols up to $98.2 \%$ and $62.15 \%$ detected by the peaks area of retention time 1.47 and 1.67 . The combination of MSOB produces large quantities of oxygen due to continuous air bubbling and BDOC are easily formed. The ozone oxidation of the formed BDOC increases very quickly as the removal rates increased and are shown in Fig. 9. The direct ozonation $1 \mathrm{~h}$ followed by MSOB treatment three, four and eight days showed a decline up to $98.95 \%$ for uracil peak area mAU. The undetected transformated products at retention time 0.487 and 0.685 achived $100 \%$ removal. The major pollutants which appeared at retention time 1.044 and 1.191 achieved $98 \%$ and $94.8 \%$ removal too. On the other hand, the HPLC chromatogram in Fig. 10 a describe the mineralization of the above pollutants after $3 \mathrm{~h}$ direct ozonation followed by MSOB up to five days. The undetected transformation products appeared at retention time 0.487 and 0.685 were $100 \%$ mineralized. The pollutants at retention time 1.044 , 1.191 and 1.395 showed removal rates reached $68 \%$, $96 \%$ and $96.6 \%$, respectively. Uracil showed removal rates reaches $46.8 \%$ compared to original sample. During transformation a slight increase in phenols peak 

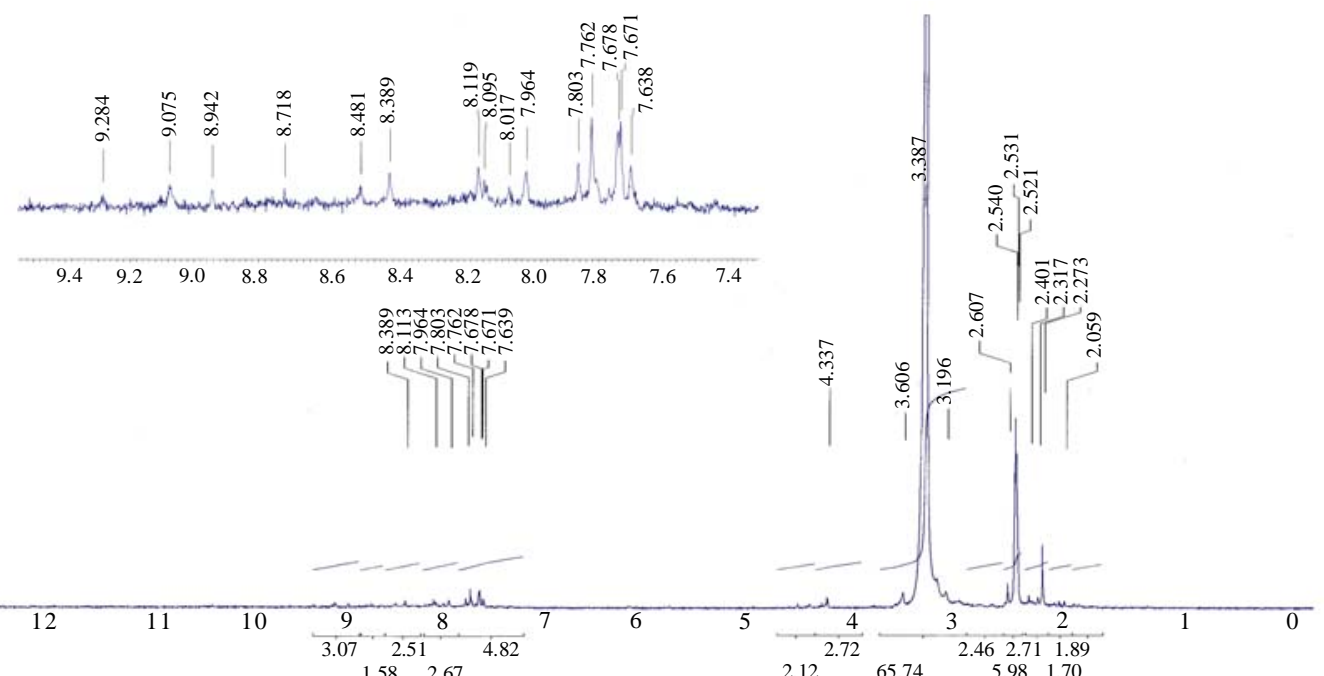

Fig 3: C-NMR chromatogram demonstrating the aromatic carbon area and ethylenic and aromatic protons of authentic redwastewater

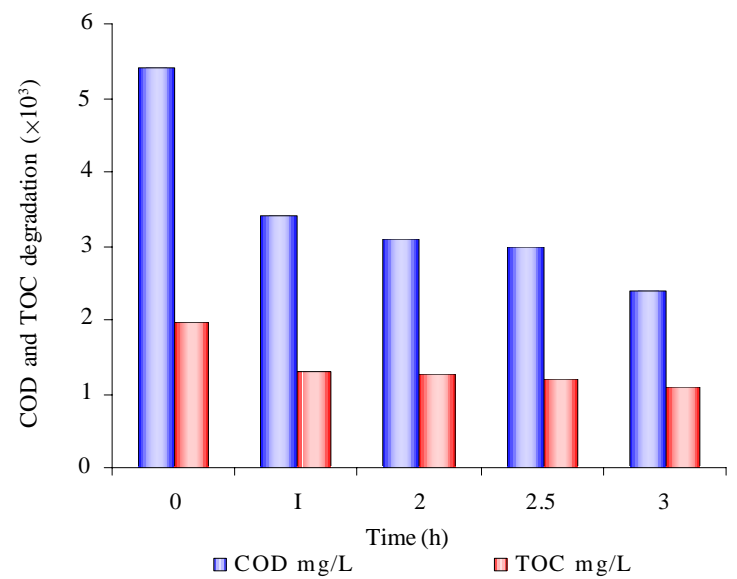

Fig. 4: Effect of direct ozonation on COD and TOC degradation in TNT synthetic solution

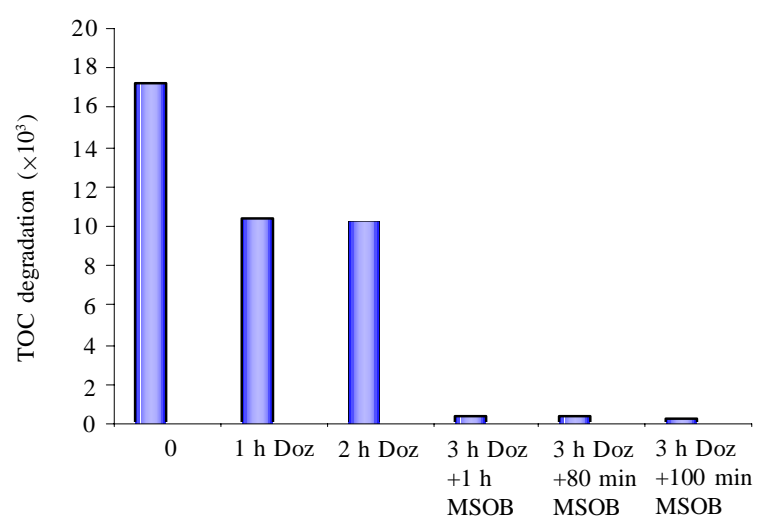

Type of treatment

Fig. 6: Effect of 3 h direct ozonation followed by MSOB treatment on TOC degradation in red water

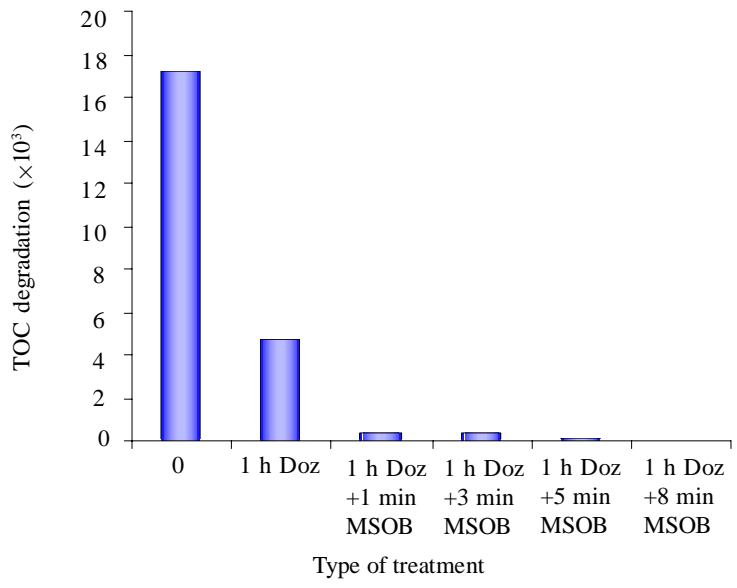

Fig. 5: Effect of $1 \mathrm{~h}$ direct ozonation followed by multistage ozonation biological treatment on TOC degradation in red water

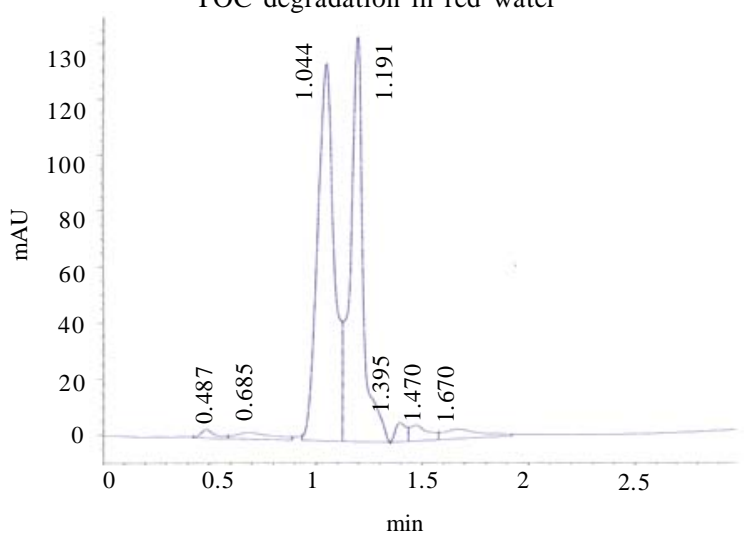

Fig 7: HPLC Chromatogram of major pollutants shown at retention -time at 1.044 and 1.191 investigated on the LC column 
area (\%) appeared. Nitrobenzene exsisted at retention time 3-4 indicated by broad peak area and continuous degradation for uracil and phenols up to $12.9 \%$ and $51.88 \%$, respectively were detected. The (MSOB) for the fifth day showed $100 \%$ removal for both undetected pollutant at retention time 0.487 and 0.685 also the major pollutants in the wastewater of retention time 1.044 and 0.191 showed $100 \%$ removal besides the complete $100 \%$ disappearance of uracil. HPLC chromatogram (Fig. 10b) illustrated the best removal of all pollutants both that were present in the original red wastewater and transformed products detected through the degradation of MSOB treatment.

\section{CONCLUSION}

Based on the above discussion, it appears that TNT and red water effluent were mineralized by ozonation and MSOB treatment. Noting that red-water is treated more easily than solid TNT. The solid TNT is to be previously hydrolysed in acetonitrile alkaline buffer solution. It is also remarkable that the complete removal of TOC can be achieved by ozonation combined with biological treatment. Besides direct ozonation is not powerful enough to mineralize materials such as TNT and red water. It may affect COD removal from wastewater till certain extent, but TOC was not easy removed and seemed to be forbidden till biological inoculation helped in dissolving organic carbon and

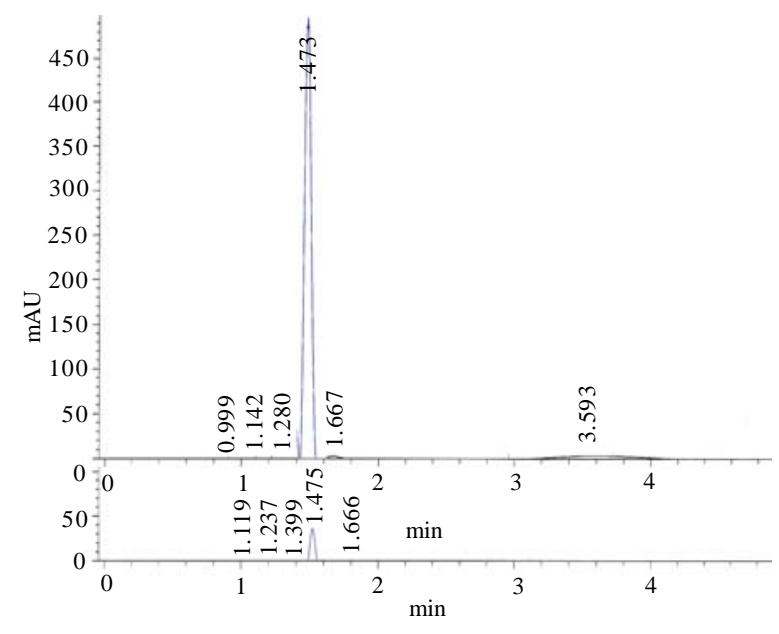

Fig 8: HPLC Chromatogram of pollutants shown at retention time investigated on the LC column after $1 \mathrm{~h}$ direct ozonation and (MSOB) treatment three days indicating main Peak of uracil and eight days indicating removal of main pollutant uracil hence facilitated complete mineralization. Addition of humic-acid to tested samples as inoculum, showed slight decrease in COD \% removal at the end of the treatment when compared to that COD \% removal achieved by river water inoculation to the same tested samples. Although both river water and humic acid addition to tested samples succeeded for biological inoculation and achieved good results in multi-stage ozone biological treatment, river water was selected as better inoculum to be added to MSOB process. Results of HPLC chromatograms proved that both $3 \mathrm{~h}$ direct ozonation followed by 3 days MSOB and $1 \mathrm{~h}$ direct ozonation followed by MSOB 5 days are powerful tools for complete destruction of pollutants present in tested samples. Three hours direct ozonation followed by MSOB 3 days shows less treatment contact time (112 h) compared to treatment contact time (121.5 h) consumed for $1 \mathrm{~h}$ direct ozonation followed by 5 days MSOB treatment.

\section{ACKNOWLEDGMENTS}

The authors gratefully thank the energetic materials producing factory for supplying with products and effluents. The author would also like to introduce his thanks to all colleagues who helped through the birth of this work in the Chemical Engineering Department, National Research Center, Egypt.

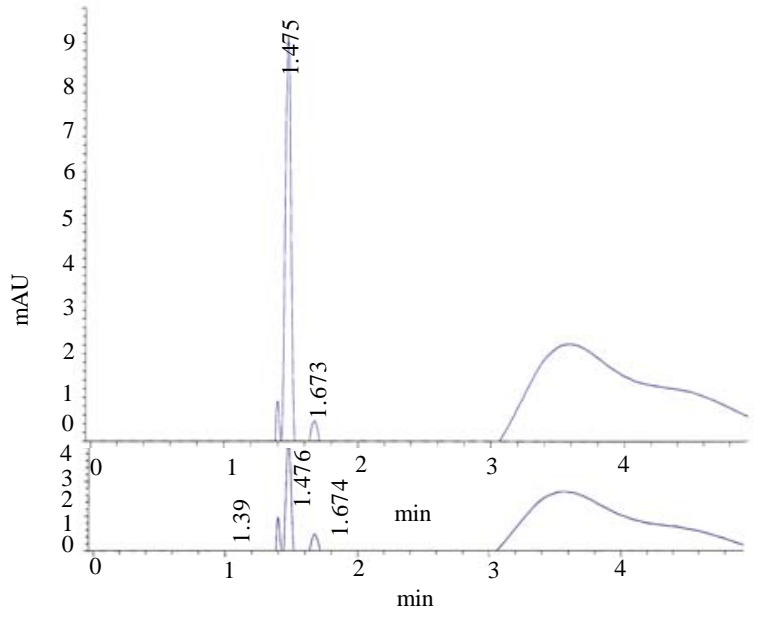

Fig 9: HPLC Chromatogram of pollutants shown at retention time investigated on the LC Column after three hours direct ozonation and (MSOB) treatment one day indicating existence of Uracil peak area. The second peack indicates (MSOB) treatment two days indicating Uracil peak area decline 
Int. J. Environ. Sci. Tech., 6 (4), 619-628, Autumn 2009

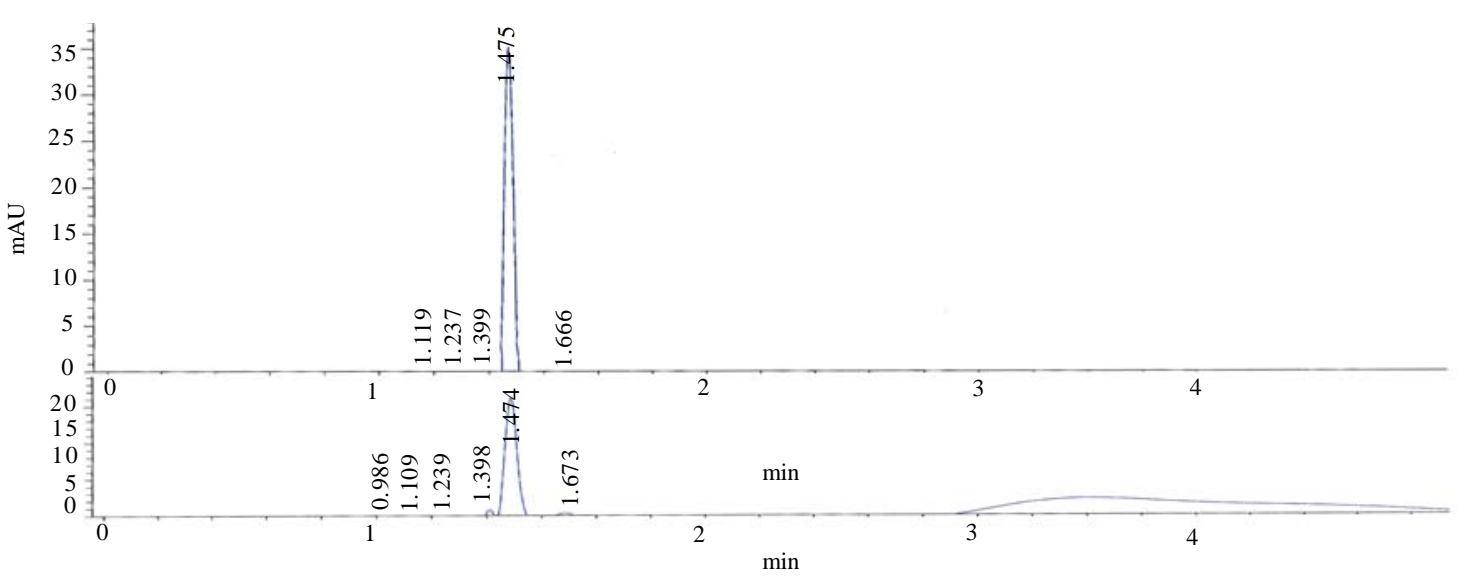

Fig. 10: HPLC chromatogram of pollutants shown at retention time investigated on the LC column after 3 h direct ozonation and MSOB treatment 3 days indicating uracil peak area of $53.22 \%$ removal. The second peak indicates (MSOB) treatment. Five days indicating uracil peak area of $89.42 \%$ removal and $34.11 \%$ removal for phenols

Table 2: C-NMR spectrum assignment

\begin{tabular}{ccl}
\hline Signal & $\begin{array}{c}\text { Chemical shift } \\
\text { range }\end{array}$ & \multicolumn{1}{c}{ Assignment } \\
\hline 7. & 7.66 & $\begin{array}{l}\text { Ethylenic and aromatic protons. } \\
\text { Gama protons in several structures } \\
\text { and alpha protons in condensed } \\
\text { structure. } \\
\text { DMSO }\end{array}$ \\
& 4.336 & Aromatic \\
10. & 3.457 & \\
11. & 2.585 & \\
12. & 2.511 & \\
13. & 2.274 & \\
14. & 2.250 & \\
15. & 2.109 & \\
16. & 2.086 & \\
17. & 1.932 & \\
\hline
\end{tabular}

\section{REFERENCES}

Adams, R. H.; Guzmán-Osorio, F. J., (2008). Evaluation of land farming and chemico-biological stabilization for treatment of heavily contaminated sediments in a tropical environment. Int. J. Environ. Sci. Tech., 5 (2), 169-178 (10 pages).

Agrawal, A.; Tratnyek, P. G., (1996). Reduction of nitroaromatic compounds by zero-valent iron metal. Environ. Sci. Tech., 30 (1), 153-160 (8 pages).

Agustina, T. E.; Ang, H. M.; Vareek, V. K., (2005). A review of synergistic effect of photocatalysis and ozonation on wastewater treatment. J. Photoch. Photobio. C, 6 (4), 264273 (10 pages).

APHA, (1999). Standard methods for the examination of water and wastewater. American Public Health Association, Method 2540A, $20^{\text {th. }}$ Ed., Washington DC., USA.

Bandstra, J. Z.; Miehr, R.; Johnson, R.; Tratnyek, P. G., (2005). Reduction of 2,4,6-trinitrotoluene by iron metal: Kinetic controls on product distributions in batch experiments. Environ. Sci. Tech., 39 (1), 230-238 (9 pages).

Barrows, S. E.; Craner, C. J.; Truhlar, D. G., (1996). Factors controlling regios selectivity in the reduction of polynitroaromatics in aqueous solution. Environ. Sci.Tech., 30 (10), 3028-3038 (11 pages).

Barreto-Rodrigues, M.; Silva, F. T.; Raiva, T. C. B., (2008). Characterization of wastewater from the Barazilian TNT industry. J. Hazard. Mater., 164 (1), 385-388 (4 pages).

Behera, S. K.; Rene, E. R.; Murthy, D. V. S., (2007). Performance of up - flow anoxic bioreactor for wastewater treatment. Int. J. Environ. Sci. Tech., 4 (2), 247-252 (6 pages).

Chang, S. J.; Liu, Y. C., (2007). Degradation mechanism of 2,4,6-trinitrotoluene in supercritical water oxidation. J. Environ. Sci., 19 (12), 1430-1435 (6 pages).

Chen, W.; Ching, W.; Lai, C., (2007). Recovery of nitrotoluenes in wastewater by solvent extraction. J. Hazard. Mater., 145 (1-2), 23-29 (6 pages).

Chen, W. S.; Juan, C. N.; Wei, K. M., (2005). Mineralization of dinitrotoluene and trinitrotoluene of spent acid in toluene nitration process by Fenton oxidation. Chemosphere, 60 (8), 1072-1079 (8 pages).

Chen, W. S.; Juan, C. N.; Wei, K. M., (2007). Decomposition of dinitrotoluene isomers and 2,4,6-trinitrotoluene in spent acid from toluene nitration process by ozonation and photoozonation. J. Hazard. Mater., 147 (1-2), 97-104 (8 pages). Esplugas, S.; Giménez, J.; Contreras, S.; Pascual, E.; Rodríguez, M., (2002). Comparison of different advanced oxidation processes for phenol degradation. Water Res., 36 (4), 1032 -1042 (11 pages).

Fahmi,W. N.; Mukaidani, T.; Okada, M., (2003). DOC removal by multi-stage ozonation-biological treatment. Water Res., 37 (1), 150-154 (5 pages).

Guest, R. K.; Smith, D. W., (2002). A potential new role for fungi in a wastewater MBR biological nitrogen reduction system. J. Environ. Eng. Sci., 1 (6), 433-437 (5 pages).

Hofstetter, T. B.; Heijman, C. G.; Haderlein, S. B.; Holliger, C.; Schwarzenbach, R. P., (1999). Complete reduction of TNT and other (poly) nitroaromatic compounds under iron-reducing 
substance conditions. Environ. Sci. Tech., 33 (9) 1479 -1487 (9 pages).

Hwang, S.; Ruff, T. J.; Bouwer, E. J.; Larson, S. L.; Davis, J. L., (2005). Applicability of alkaline hydrolysis for remediation of TNT-Contaminated water, Water Res., 39 (18), 4503-4511 (9 pages).

Imo, T. S.; Oomori, T.; Toshihiko, M.; Tamaki, F., (2007). The comparative study of trihalomethanes in drinking waters. Int. J. Environ. Sci. Tech., 4 (4), 421-426 (6 pages).

Jarvis, A. S.; Mc Farland, V. A.; Honeycutt, M. E., (1998). Assessment of the effectiveness of composting for the reduction of toxicity and mutagenicity of explosive contaminated soil. Ecotoxicol. Environ. Saf., 39 (2), 131 -135 (5 pages).

Li, Z. M.; Shea, P .J.; Comfort, S. D., (1998). Nitrotoluene destruction by UV - catalyzed Fenton oxidation. Chemosphere, 36 (8), 1849 -1865 (17 pages).

Lin, S. H.; Kiang, C. D., (2003). Combined physical and biological treatments of wastewater containing organics from a semiconductor plant. J. Hazard. Mater., 97 (1-3), 159-171 (13 pages).

Material Data Inc. Jade 6.0 (2003). X-ray pattern processing for the PC, Liver more, CA, 1995-2003.

Peyton, G. R.; Glaze, W. H., (1988). Destruction of pollutants in water with ozone in combination with ultraviolet radiation.3. photolysis of aqueous ozone. Environ. Sci. Tech., 22 (7), 761767 (7 pages).

Rauch, T.; Drewes, J. E., (2005). Quantifying biological organic carbon removal in groundwater recharge systems. J. Envir. Eng., 131 (6), 909-923 (15 pages).

Sivakumar, M.; Takake, P. A.; Pandit, A. B., (2002). Kinetics of p-nitrophenol degradation. Effect of reaction conditions and cavitational parameters for a multiple frequency system. Chem. Eng. J., 85 (2-3), 327- 338 (12 pages).

Song, S.; Xia, M.; He, Z.; Ying, H.; Lü, B.; Chen, J., (2007). Degradation of p-nitrotoluene in aqueous solution by ozonation combined with sonoloysis. J. Hazard. Mater., 144 (1-2), 532537 (6 pages).

Sotelo, J. L.; Beltran, F. J., (1989). Hery‘s law constant for the ozone - water system. Water Res., 23 (10), 1239 - 1246 (8 pages).

Svanström, M.; Fröling, M.; Modell, M.; Peters, W. A.; Tester, J., (2004). Environmental assessment of supercritical water oxidation of sewage sludge. Resour. Conserv. Recy., 41 (4), 321 - 338 (18 pages).

Thorn, K. A.; Thorn, P. G.; Cox, L. G., (2004). Alkaline hydrolysis / polymerization of 2,4,6-trinitrotoluene : Characterization of products by ${ }^{13} \mathrm{C}$ and ${ }^{15} \mathrm{~N}$ NMR. Environ. Sci. Tech., 38 (7), 2224- 2231 (8 pages).

USEPA, (2000). Drinking Water Standards and Health Advisories. US Environmental Protection Agency. Office of Water 4304 EPA 822-B-00-001, Washington, DC, USA.

USEPA, (2002). Nitroaromatic and nitrosamines by high performance liquid chromatography (HPLC). US Environmental Protection Agency, Method 8330, Washington, DC, USA.

Vohara, M. S.; Tanaka, K., (2002). Photocatalytic degradation of nitrotoluene in aqueous $\mathrm{TiO}_{2}$ suspention. Water Res., 36 (1), 59-64 (6 pages).

Won, W. D.; Disalvo, L. H., Ng, J., (1976). Toxicity and Mutagenicity of 2,4,6-trinitrotoluene and its microbial metabolites. Appl. Environ. Microbiol., 31 (4), 576-580 (5 pages).

Yardin, G.; Chiron, S., (2006). Photo-Fenton treatment of TNT contaminated soil extract solutions obtained by soil flushing with cyclodextrin. Chemosphere, 62 (9), 1395 - 402 (8 pages).

Yasiu, H.; Miyaji, Y., (1992). A novel approach to removing refractory organic compounds in drinking water. Water Sci. Tech., 26 (7-8), 1503-1512 (10 pages).

Yasiu, H.; Miyaji, Y., (1992). A novel approach to removing refractory organic compounds in drinking water. Water Sci. Tech., 26 (7-8), 1503-1512 (10 pages).

\section{AUTHOR (S) BIOSKETCHES}

El Diwani, G., Ph.D., Professor of chemical engineering, National Research Center, Department of Chemical Engineering, Egypt. Email:geldiwani@yahoo.com

El Rafie, S., Ph.D., Assistant professor of Chemistry, National Research Center, Department of Chemical Engineering, Egypt. Email: shelrafie0000@yahoo.com

Hawash, S., Ph.D., Professor of chemical engineering, National Research Center, Department of Chemical Engineering, Egypt. Email: dr_shawash@yahoo.com

\footnotetext{
How to cite this article: (Harvard style)

El Diwani, G.; El Rafie, S.; Hawash, S., (2009). Degradation of 2, 4, 6-trinitotoluene in aqueous solution by ozonation and multi-stage ozonation-biological treatment. Int. J. Environ. Sci. Tech., 6 (4), 619-628.
} 